\title{
Host-specific assemblages typify gut microbial communities of related insect species
}

\author{
Zakee L Sabree ${ }^{1,2^{*}}$ and Nancy A Moran ${ }^{1,3}$
}

\begin{abstract}
Mutualisms between microbes and insects are ubiquitous and facilitate exploitation of various trophic niches by host insects. Dictyopterans (mantids, cockroaches and termites) exhibit trophisms that range from omnivory to strict wood-feeding and maintain beneficial symbioses with the obligate endosymbiont, Blattabacterium, and/or diverse gut microbiomes that include cellulolytic and diazotrophic microbes. While Blattabacterium in omnivorous Periplaneta is fully capable of provisioning essential amino acids, in wood-feeding dictyopterans it has lost many genes for their biosynthesis (Mastotermes and Cryptocercus) or is completely absent (Heterotermes). The conspicuous functional degradation and absence of Blattabacterium in most strict wood-feeding dictyopteran insects suggest that alternative means of acquiring nutrients limited in their diet are being employed. A 16S rRNA gene amplicon resequencing approach was used to deeply sample the composition and diversity of gut communities in related dictyopteran insects to explore the possibility of shifts in symbiont allegiances during termite and cockroach evolution. The gut microbiome of Periplaneta, which has a fully functional Blattabacterium, exhibited the greatest within-sample operational taxonomic unit (OTU) diversity and abundance variability than those of Mastotermes and Cryptocercus, whose Blattabacterium have shrunken genomes and reduced nutrient provisioning capabilities. Heterotermes lacks Blattabacterium and a single OTU that was 95\% identical to a Bacteroidia-assigned diazotrophic endosymbiont of an anaerobic cellulolytic protist termite gut inhabitant samples consistently dominates its gut microbiome. Many host-specific OTUs were identified in all host genera, some of which had not been previously detected, indicating that deep sampling by pyrotag sequencing has revealed new taxa that remain to be functionally characterized. Further analysis is required to uncover how consistently detected taxa in the cockroach and termite gut microbiomes, as well as the total community, contribute to host diet choice and impact the fate of Blattabacterium in dictyopterans.
\end{abstract}

Keywords: Cockroaches; Termites; Gut microbiota; Blattabacterium

\section{Background}

Successful collaborations between microbes and their arthropod hosts have enabled exploitation of a wide range of trophic niches. Maternally inherited intracellular bacteria and/or gut-inhabiting microbial assemblages involved in host nutrition are found in insects that persist on specialized (e.g. plant juices, animal blood, wood or decaying plant material) or omnivorous diets (Moran et al. 2008; Hongoh 2010). Cockroaches (Dictyoptera: Blattaria) are host to both an obligate intracellular symbiont and a species-rich gut microbial community, while

\footnotetext{
* Correspondence: sabree.8@osu.edu

${ }^{1}$ Department of Ecology and Evolutionary Biology, Yale University, New Haven, CT 06511, USA

${ }^{2}$ Department of Evolution, Ecology and Organismal Biology, The Ohio State University, Columbus, $\mathrm{OH}$ 43210, USA

Full list of author information is available at the end of the article
}

most termites (Dictyoptera: Isoptera) host only the latter (Lo et al. 2003; Hongoh 2010; Schauer et al. 2012). Nearly all cockroaches harbor the intracellular mutualist, Blattabacterium sp. (heretofore referred to as Blattabacterium), which has codiversified with their insect hosts over millions of years and in most cases they can recycle nitrogen from ammonia and urea metabolic wastes into the production of essential and nonessential amino acids (Sabree et al. 2009). Termites share a common ancestor with the wood roach Cryptocercus spp. (heretofore referred to as Cryptocercus) via Mastotermes darwiniensis (heretofore referred to as Mastotermes), which forms the basal branch in termite phylogenies, and as such these species represent transitional stages between cockroaches and termites. When compared to their modern cockroach relatives, termites sport several striking distinctions that 
include advanced social behaviors, dramatic physiological modifications (e.g. enlarged hindguts, perpetual neoteny, thin cuticles) (Nalepa 2011) and, with Mastotermes as the only known exception, loss of the heritable Blattabacterium symbiont (Bell et al. 2007). Cryptocercus and Mastotermes, also exhibit many of these characteristics and retain Blattabacterium (Neef et al. 2011; Sabree et al. 2012). It is surprising that the genomes of Blattabacterium in these two host insects lack genes involved in the biosynthesis of some essential amino acids, given that their hosts are limited for nitrogen given that they thrive on wood-based diets typically low in protein (0.03-0.7\% nitrogen (Merrill \& Cowling 1966; Tayasu et al. 1994)). Many intracellular bacterial mutualists of phytophagous insects with highly reduced genomes still retain essential amino acid biosynthesis pathway presumably to supplement their low nitrogen diet (Sabree et al. 2013). Thus, the functional deterioration of Blattabacterium in Cryptocercus and $M$. darwiniensis and its complete elimination in other termites suggest alternative means of obtaining and retaining nitrogen in these insects.

Emergent mutualisms with gut microbes that can provide the same nutrients as the ancient endosymbiont while conferring new functions may have been a context for functional deterioration and eventual loss of Blattabacterium in Cryptocercus and Mastotermes and termites, respectively. Supporting evidence in this regard would be the discovery of nitrogen fixation in termites (Benemann 1973), its association with hindgut bacteria (Yamada et al. 2007; Potrikus \& Breznak 1977; Kudo et al. 1998; Ohkuma et al. 1999), and identification of genes underlying nitrogen fixation and essential amino acid biosynthesis in hindgut bacteria in various termite species (Wertz et al. 2012; Isanapong et al. 2012). Additionally, 'lower' termites and Cryptocercus are aided in their trophic specialization on wood by lignocellulosic hindgut microbes that include both bacteria (Hongoh 2010; Mattéotti et al. 2011; Abt et al. 2012) and protists (Tartar et al. 2009; Scharf et al. 2011; Carpenter et al. 2011; Tamschick \& Radek 2013). These protists are themselves hosts to intra- and extra-cellular bacterial symbionts (Hongoh et al. 2008a; Hongoh et al. 2008b; Desai \& Brune 2012; Strassert et al. 2012). Since Blattabacterium can neither degrade cellulose nor fix nitrogen, acquisition of organisms capable of these functions enables their host to exploit an abundant dietary substrate and represents a significant improvement on resource utilization afforded by Blattabacterium.

A 16S rRNA gene amplicon resequencing approach (Schloss \& Handelsman 2003; Tringe \& Hugenholtz 2008) was used to deeply sample the composition and diversity of gut communities in dictyopteran insects to explore the possibility of shifts in symbiont allegiances during the evolution of termites from cockroaches. We expected that if Cryptocercus and termites are reliant upon their gut microbiomes in the context of a functionally diminished or absent Blattabacterium, respectively, then their community profiles will be stable across intraspecific individuals and abundant bacterial operational taxonomic unit (OTU) therein would be consistently detected. Additionally, metabolic profiles and available genomic information from taxa related to abundant gut microbiome members detected in this study were used to make general inferences about their possible roles in host trophic ecology.

\section{Results and discussion}

Sampling effort, community diversity analysis and general taxonomic profiling

The gut microbiota of two termite and two cockroach species were surveyed by pyrosequencing to identify and quantify community membership, and to compare intraand inter-host community profiles in the context of 1) the host's diet, 2) presence or absence of Blattabacterium and 3) the inferred functional capacity of Blattabacterium. A total of 276,850 high-quality pyrotags representative of $16 \mathrm{~S}$ rRNA gene V6-V9 region amplicons were clustered into 1,152 OTUs and included in subsequent analyses (Additional file 1:Table S1). Observed and estimated OTU richness and rarefaction analyses suggest that nearcomprehensive sampling of the termite and Cryptocercus microbiota could be achieved in fewer than 35,000 pyrotags, but this may not be sufficient for the Periplaneta microbiota due to the relatively high OTU richness therein (Table 1; Additional file 2: Figure S1).

Sequences representative of each of the 1,152 OTUs were taxonomically classified by comparing them to SILVA (version 108;) and nr (accessed May 6, 2012) databases using blastn. OTUs were assigned to over 24 bacterial phyla that include Fusobacteria, Deferribacteres, Cyanobacteria, Verrucomicrobia, Elusimicrobia, TM7, Planctomycetes, Tenericutes, Synergistetes, Actinobacteria, Spirochaetes, Proteobacteria, Bacteroidetes, and Firmicutes (Figure 1; Table 2). Single OTUs assigned to the Bacteroidia and Clostridia classes were abundant (defined as $>1 \%$ ) in every sample, and, when combined, predominant in all four host species (Additional file 3: Table S2). Bacilli, Elusimicrobia, Deltaproteobacteria and Spirochaetes OTUs were detected, but they were not uniformly abundant, in every sample. With some exceptions, OTUs assigned to many of the remaining families were not abundant (i.e. $<1 \%$ ) and/or were absent from some samples or sample groups.

\section{Predominant taxa are host specific and consistently abundant}

OTUs assigned to the Bacteroidia predominate in nearly all host gut communities but few were shared between cockroaches and termites (Table 2). Similarly, Clostridia were abundant in every host, but to lesser degree 
Table 1 Insect gut community alpha diversity

\begin{tabular}{lcccccc}
\hline Sample & Pyrotags & Observed OTUs & Species richness & OTU $_{\text {obs }} /$ OTU $_{\text {ACE }}$ & Species evenness $^{\text {Average distance }}$ \\
\hline Ha01 & 33427 & 189 & $191.19(+/-4.5)$ & 0.99 & $2.50(+/-0.04)$ \\
Ha02 & 30441 & 150 & $171.85(+/-17.0)$ & 0.87 & $1.18(+/-0.01)$ & $1.85(+/-0.02)$ \\
Ha03 & 34266 & 191 & $199.90(+/-9.6)$ & 0.96 & $18.44(+/-0.6)$ \\
Md01 & 16610 & 287 & $294.43(+/-7.7)$ & 0.97 & $35.33(+/-1.0)$ & Ha: 0.23 \\
Md02 & 14964 & 303 & $316.55(+/-11.1)$ & 0.96 & $20.41(+/-0.5)$ \\
Md03 & 14086 & 254 & $268.44(+/-11.6)$ & 0.95 & $39.65(+/-1.6)$ \\
Cp01 & 12476 & 319 & $329.65(+/-9.4)$ & 0.97 & $24.35(+/-1.0)$ \\
Cp02 & 14482 & 321 & $338.55(+/-12.6)$ & 0.95 & $34.71(+/-1.4)$ \\
Cp03 & 12504 & 334 & $341.44(+/-7.5)$ & 0.98 & $16.08(+/-0.4)$ \\
PaW01 & 20767 & 275 & $314.39(+/-22.7)$ & 0.87 & $32.38(+/-4.2)$ \\
PaW02 & 2081 & 225 & $282.93(+/-29.9)$ & 0.80 & $26.39(+/-0.7)$ \\
PaW03 & 30565 & 391 & $401.13(+/-9.2)$ & 0.97 & $54.68(+/-4.5)$ \\
PaL01 & 4208 & 299 & $342.61(+/-23.2)$ & 0.87 & $44.60(+/-2.0)$ \\
PaL02 & 11801 & 364 & $380.07(+/-11.6)$ & 0.96 & $60.96(+/-1.3)$ \\
PaL03 & 24172 & 384 & $400.78(+/-12.3)$ & 0.96 & PaW: 0.57 \\
\hline
\end{tabular}

Species richness was estimated using the abundance coverage estimator (ACE) and evenness was demonstrated as the inverse of Simpson's estimation of evenness. 95\% confidence indicators are noted in parenthesis for both measures. Ha-Heterotermes aureus, Md-Mastotermes darwiniensis, Cp-Cryptocercus punctulatus, PaW-Periplaneta americana wild-caught, PaL-P. americana lab-reared.

1-Average within-group sample distances were calculated using Multi-Response Permutation Procedures using the Bray-Curtis distance measure.

Test statistic: -8.719 , observed delta: 0.4142 , expected delta: 0.8829 , chance-corrected within group agreement: 0.5309, P-value: $7.0 \mathrm{e}-8$.

(representing $<4 \%$ of the total OTUs) in $H$. aureus. Like the Bacteroidia-assigned OTUs, none were shared across both termites and cockroaches. Given that 59-96\% of the pyrotags in each sample could be assigned to either class, yet few OTUs were shared, the observed host-defined sample clustering in the NMS analysis is not unexpected (Figure 2). It is not surprising to find members of both classes in all of the gut microbiomes of hosts in this study

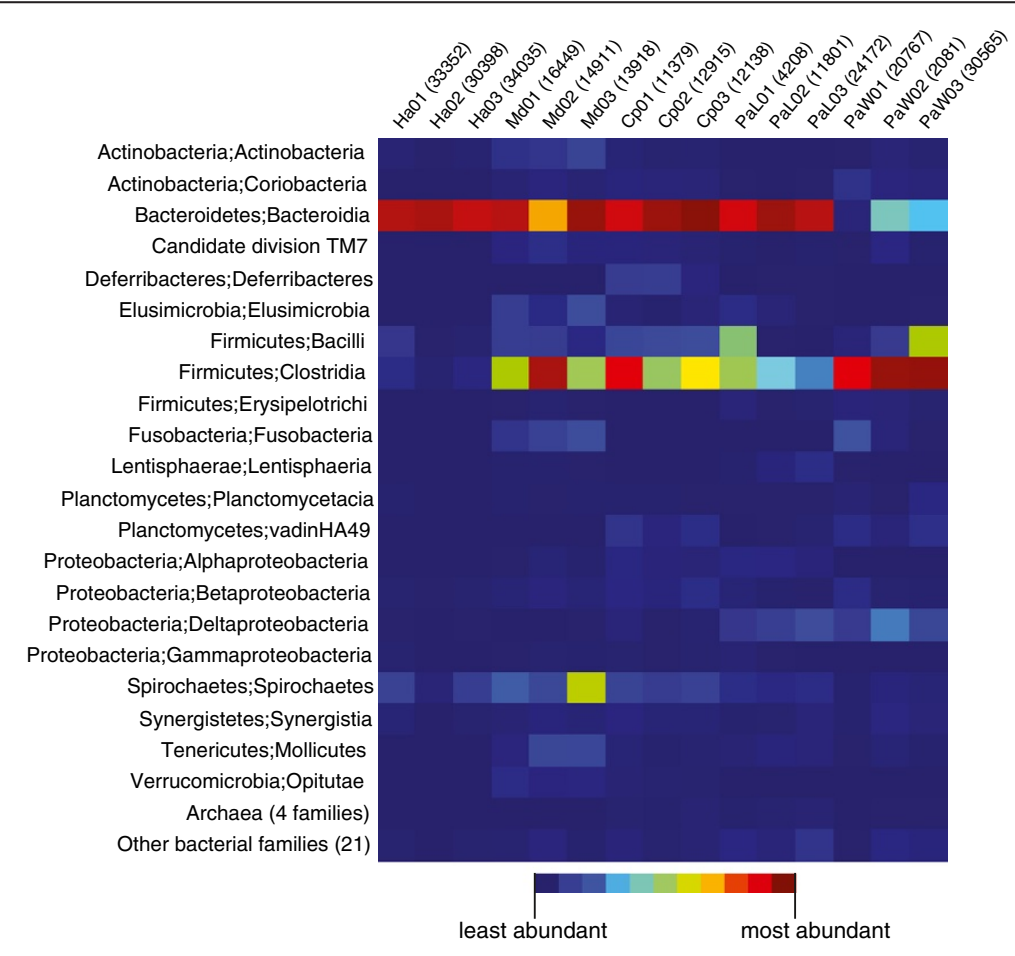

Figure 1 Bacteroidia and Clostridia predominate in most cockroach and termite gut microbiota. Heatmap depicts the relative abundances of pyrotags assigned to each taxonomic class; total number of pyrotags representative of each sample are parenthesized. 
Table 2 Relative abundance of bacterial families present within insect gut communities

\begin{tabular}{|c|c|c|c|c|c|c|c|c|c|c|c|c|c|c|c|}
\hline $\begin{array}{l}\text { Taxonomic } \\
\text { designation }\end{array}$ & $\mathrm{HaO1}$ & $\mathrm{HaO2}$ & $\mathrm{HaO3}$ & Md01 & Md02 & Md03 & Cp01 & Cp02 & Cp03 & PaL01 & PaL02 & PaL03 & PaW01 & PaW02 & PaW03 \\
\hline $\begin{array}{l}\text { Actinobacteria; } \\
\text { Actinobacteria }\end{array}$ & $1.06(8)$ & $0.23(7)$ & $1.01(8)$ & $2.74(8)$ & $2.74(10)$ & $4.14(9)$ & $0.70(10)$ & $0.37(10)$ & $0.49(9)$ & n.d. (0) & n.d. (0) & n.d. (1) & $0.18(6)$ & $0.91(7)$ & $0.51(8)$ \\
\hline $\begin{array}{l}\text { Actinobacteria; } \\
\text { Coriobacteria }\end{array}$ & $0.05(2)$ & $0.02(2)$ & $0.01(2)$ & $0.55(3)$ & $1.21(3)$ & $0.47(3)$ & $1.00(4)$ & $1.07(4)$ & $0.86(4)$ & $0.12(2)$ & $0.08(2)$ & $0.13(2)$ & $4.49(2)$ & $1.44(2)$ & $0.99(2)$ \\
\hline $\begin{array}{l}\text { Bacteroidetes; } \\
\text { Bacteroidia }\end{array}$ & $75.83(21)$ & $95.68(17)$ & $83.53(18)$ & $42.41(52)$ & $28.31(51)$ & $33.95(50)$ & $36.66(46)$ & $48.57(50)$ & $44.71(50)$ & $41.02(89)$ & 58.21 (88) & $56.59(100)$ & $1.51(50)$ & $19.75(55)$ & $14.83(88)$ \\
\hline $\begin{array}{l}\text { Candidate } \\
\text { division TM7 }\end{array}$ & $0.04(2)$ & $0.01(1)$ & $0.04(2)$ & 1.53 (13) & $2.22(14)$ & $0.94(11)$ & $1.08(12)$ & $1.09(10)$ & $0.65(8)$ & $0.26(4)$ & $0.09(3)$ & $0.31(6)$ & $0.31(5)$ & $1.87(7)$ & $0.29(6)$ \\
\hline $\begin{array}{l}\text { Deferribacteres; } \\
\text { Deferribacteres }\end{array}$ & n.d. (0) & n.d. (0) & n.d. (0) & n.d. (0) & n.d. (0) & n.d. (0) & $3.51(1)$ & $4.81(1)$ & $1.45(1)$ & $0.02(1)$ & $0.23(2)$ & $0.23(2)$ & n.d. (0) & n.d. (0) & $0.05(2)$ \\
\hline $\begin{array}{l}\text { Elusimicrobia; } \\
\text { Elusimicrobia }\end{array}$ & $0.04(2)$ & $0.01(2)$ & $0.02(2)$ & $4.31(8)$ & $1.87(9)$ & $6.07(7)$ & $0.57(2)$ & $0.26(3)$ & $0.8(2)$ & $2.16(5)$ & $1.07(5)$ & $0.26(3)$ & $0.01(1)$ & $0.05(1)$ & $0.1(3)$ \\
\hline $\begin{array}{l}\text { Firmicutes; } \\
\text { Bacilli }\end{array}$ & $5.92(9)$ & $0.2(7)$ & 0.81 (11) & $4.18(5)$ & $3.47(5)$ & $1.54(4)$ & $5.79(9)$ & $7.88(8)$ & $7.98(8)$ & $20.29(7)$ & $0.24(5)$ & $0.01(2)$ & $1.54(8)$ & $4.13(6)$ & $24.8(10)$ \\
\hline $\begin{array}{l}\text { Firmicutes; } \\
\text { Clostridia }\end{array}$ & $4.00(67)$ & $1.05(50)$ & $3.11(67)$ & $24.75(97)$ & 38.2 (109) & 17.7 (84) & $35.02(140)$ & 24.5 (138) & $29.19(147)$ & $22.98(117)$ & $22.4(151)$ & $15.86(151)$ & $61.81(142)$ & $48.82(100)$ & 44.06 (186) \\
\hline $\begin{array}{l}\text { Firmicutes; } \\
\text { Erysipelotrichi }\end{array}$ & n.d. (0) & n.d. (0) & n.d. (0) & $0.16(2)$ & $0.43(2)$ & $0.07(2)$ & $0.05(1)$ & $0.09(1)$ & $0.02(1)$ & $0.9(6)$ & $0.23(7)$ & $0.55(7)$ & $1.58(5)$ & $0.96(3)$ & $0.4(5)$ \\
\hline $\begin{array}{l}\text { Fusobacteria; } \\
\text { Fusobacteria }\end{array}$ & n.d. (0) & n.d. (0) & n.d. (0) & $3.00(1)$ & $4.25(1)$ & $6.12(1)$ & n.d. (0) & n.d. (0) & n.d. (0) & $0.02(1)$ & n.d. (0) & n.d. (0) & $13.71(1)$ & $1.11(1)$ & $0.22(1)$ \\
\hline $\begin{array}{l}\text { Lentisphaerae; } \\
\text { Lentisphaeria }\end{array}$ & n.d. (0) & n.d. (0) & n.d. (0) & $0.30(3)$ & $0.25(3)$ & $0.1(2)$ & n.d. (0) & n.d. (0) & n.d. (0) & $0.26(4)$ & $1.49(5)$ & $3.17(5)$ & $0.18(2)$ & n.d. (0) & $0.08(2)$ \\
\hline $\begin{array}{l}\text { Planctomycetes; } \\
\text { Planctomycetacia }\end{array}$ & $0.43(2)$ & $0.01(1)$ & $0.13(2)$ & $0.24(3)$ & $0.12(2)$ & $0.19(3)$ & $0.24(1)$ & $0.26(2)$ & $0.12(2)$ & $0.12(3)$ & $0.29(6)$ & $0.14(5)$ & $0.83(5)$ & $0.19(4)$ & $1.85(6)$ \\
\hline $\begin{array}{l}\text { Planctomycetes; } \\
\text { vadinHA49 }\end{array}$ & $0.04(1)$ & $0.03(1)$ & $0.11(1)$ & n.d. (0) & n.d. (0) & n.d. (0) & $2.65(4)$ & 1.49 (3) & $2.36(4)$ & $0.05(2)$ & $0.28(5)$ & $0.67(5)$ & $3.29(4)$ & $1.06(4)$ & $2.65(5)$ \\
\hline $\begin{array}{l}\text { Proteobacteria; } \\
\text { Alphaproteo- } \\
\text { bacteria }\end{array}$ & $0.08(4)$ & $0.06(3)$ & $0.04(4)$ & $0.14(6)$ & $0.61(9)$ & $0.24(4)$ & $1.62(15)$ & $1.17(14)$ & $0.86(14)$ & $1.88(9)$ & $2.3(14)$ & $1.42(16)$ & $0.03(3)$ & $0.1(1)$ & $0.04(5)$ \\
\hline $\begin{array}{l}\text { Proteobacteria; } \\
\text { Betaproteobacteria }\end{array}$ & $0.70(5)$ & $0.42(6)$ & $0.71(6)$ & $0.73(5)$ & $1.22(5)$ & $0.6(4)$ & $1.52(7)$ & $1.36(9)$ & $2.39(9)$ & $0.71(3)$ & $0.36(6)$ & $0.19(6)$ & $3.39(6)$ & $0.43(1)$ & $0.27(3)$ \\
\hline $\begin{array}{l}\text { Proteobacteria; } \\
\text { Deltaproteo- } \\
\text { bacteria }\end{array}$ & $0.35(5)$ & $0.06(5)$ & $0.41(6)$ & $0.02(1)$ & $0.03(1)$ & $0.15(1)$ & $0.85(9)$ & $0.16(7)$ & $0.46(8)$ & $3.26(20)$ & $5.94(26)$ & $10.38(32)$ & $5.84(20)$ & $12.88(15)$ & $5.69(26)$ \\
\hline $\begin{array}{l}\text { Proteobacteria; } \\
\text { Gammaproteo- } \\
\text { bacteria }\end{array}$ & $0.59(2)$ & $0.01(1)$ & $0.1(2)$ & $0.22(2)$ & $0.34(3)$ & $0.23(2)$ & $0.35(4)$ & $0.19(6)$ & $0.42(6)$ & $0.64(2)$ & $0.18(1)$ & n.d. (0) & $0.03(2)$ & $0.05(1)$ & $0.04(2)$ \\
\hline $\begin{array}{l}\text { Spirochaetes; } \\
\text { Spirochaetes }\end{array}$ & 8.84 (39) & $1.87(32)$ & $8.34(40)$ & 9.67 (45) & $5.93(39)$ & $20.02(42)$ & 4.74 (15) & 4.47 (15) & $4.88(16)$ & $2.38(7)$ & $2.69(11)$ & $2.96(12)$ & $0.43(1)$ & $1.3(4)$ & $0.72(6)$ \\
\hline
\end{tabular}


Table 2 Relative abundance of bacterial families present within insect gut communities (Continued)

\begin{tabular}{|c|c|c|c|c|c|c|c|c|c|c|c|c|c|c|c|}
\hline $\begin{array}{l}\text { Synergistetes; } \\
\text { Synergistia }\end{array}$ & $1.24(5)$ & $0.12(5)$ & $0.75(5)$ & $0.55(7)$ & $1.09(8)$ & $0.6(7)$ & $1.31(5)$ & $0.77(5)$ & $0.79(5)$ & $0.26(2)$ & $0.47(4)$ & $1.21(4)$ & $0.35(3)$ & $1.78(2)$ & $0.81(3)$ \\
\hline $\begin{array}{l}\text { Tenericutes; } \\
\text { Mollicutes }\end{array}$ & $0.01(1)$ & $0.02(1)$ & $0.02(1)$ & $1.42(7)$ & $5.02(7)$ & $4.87(5)$ & $0.66(7)$ & $0.33(6)$ & $0.47(8)$ & $0.64(4)$ & $1.55(4)$ & $1.25(5)$ & $0.22(3)$ & $0.86(3)$ & $0.25(5)$ \\
\hline $\begin{array}{l}\text { Verrucomicrobia; } \\
\text { Opitutae }\end{array}$ & $0.02(1)$ & $0.01(1)$ & $0.03(1)$ & $2.30(5)$ & $1.3(4)$ & $1.27(5)$ & $0.55(6)$ & $0.53(7)$ & $0.31(8)$ & $0.07(1)$ & $0.08(2)$ & $0.05(2)$ & n.d. (0) & $0.05(1)$ & $0.04(1)$ \\
\hline $\begin{array}{l}\text { Other bacterial } \\
\text { families } \\
\text { ( } 21 \text { families) }\end{array}$ & $0.77(8)$ & $0.19(5)$ & $0.83(8)$ & $0.52(10)$ & $1.14(14)$ & $0.19(5)$ & $0.98(12)$ & $0.38(12)$ & $0.61(14)$ & $1.69(9)$ & $1.2(14)$ & $3.88(16)$ & $0.2(4)$ & 2.07 (5) & $1.22(12)$ \\
\hline $\begin{array}{l}\text { Archaea } \\
\text { (4 families) }\end{array}$ & n.d. (0) & n.d. (0) & n.d. (0) & $0.25(3)$ & $0.25(3)$ & $0.54(2)$ & $0.14(2)$ & $0.26(3)$ & 0.17 (3) & $0.26(1)$ & $0.64(3)$ & $0.73(2)$ & $0.06(2)$ & $0.19(2)$ & $0.1(4)$ \\
\hline
\end{tabular}

Values represent the percentage of all taxonomically-assigned OTUs within each sample. Parenthesized values represent the real number of OTUs within each sample assigned to that taxonomic group. n.d.-not detected. 


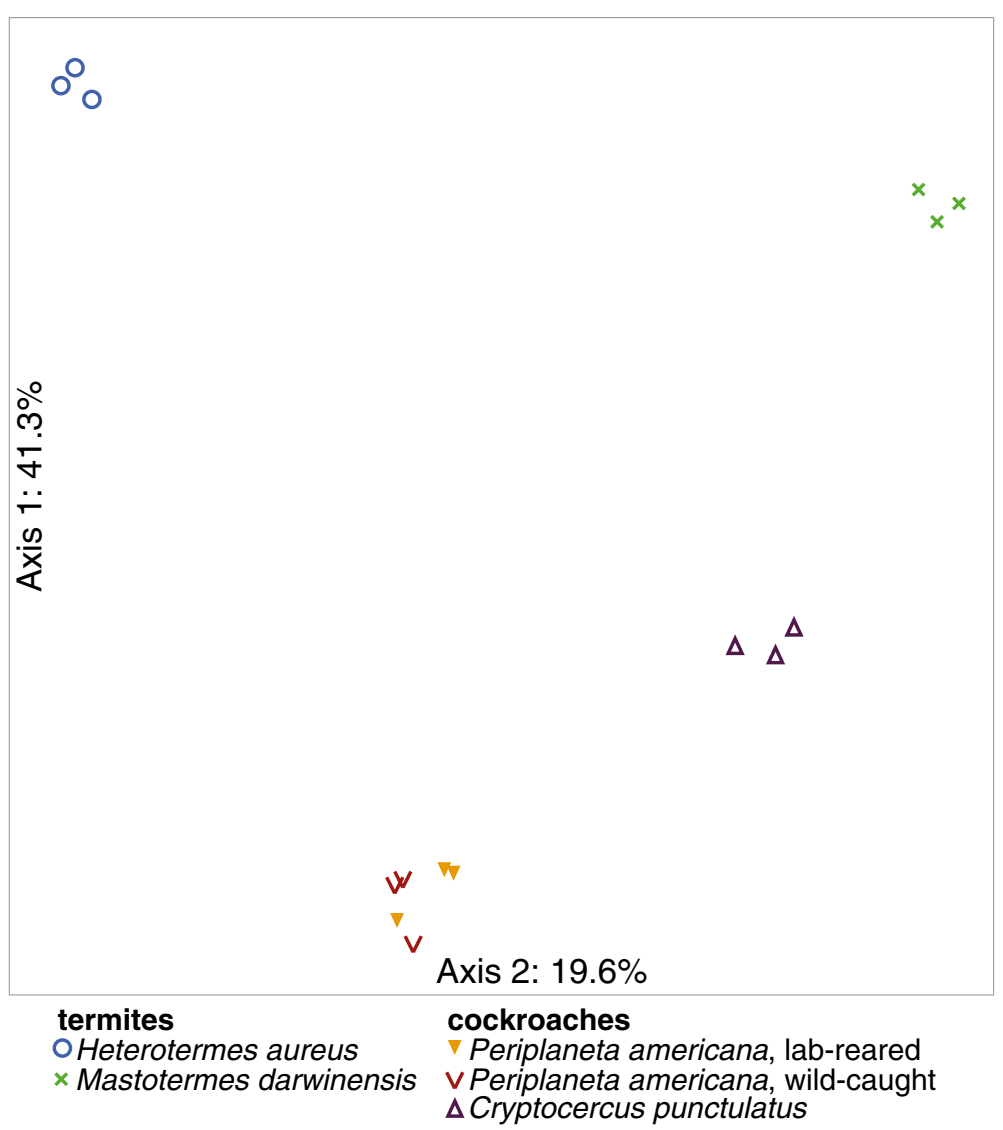

Figure 2 Insect community samples form host-defined clusters. Nonmetric multidimensional scaling was used to visualize community diversity and relatedness. A randomly subsampled, size-normalized $(n=2,050)$ pyrotag abundance data table was used.

as cultivated bacteroidia and clostridia 1) range from aerotolerant to strict anaerobes, exhibit a wide range of potentially host-beneficial carbon fermentative metabolisms, including cellulose degradation by various clostridial genera (Tracy et al. 2012), 2) are well-adapted to the dynamic gut environment and 3) are common amongst the gut flora of healthy invertebrates and vertebrates (Schleifer 2009; Engel \& Moran 2013).

OTUs assigned to the Tenericutes and Elusimicrobia were abundant only in Mastotermes. Members of the Tenericutes, namely Phytoplasma, Mycoplasma and Spiroplasma are well-adapted to reside in various animal and plant hosts largely as pathogens (Garnier et al. 2001; Gasparich 2010) but a recent report of Spiroplasma conferring protection against parasitic nematodes in some Drosophila species (Haselkorn et al. 2013) indicates other interactions between tenericutes and their eukaryotic hosts are possible.

Members of the Elusimicrobia were initially detected in Reticulitermes speratus hindguts (Ohkuma \& Kudo 1996; Hongoh et al. 2003) and have since been detected in the guts of various phytophagous insects and terrestrial habitats (Herlemann et al. 2007). Elusimicrobium minutum was the first cultivated member of this clade (Geissinger et al. 2009) and this strict anaerobe generates ATP through typical fermentative pathways and generates some amino acids but likely relies upon other microbiome members, the host or the host's diet for additional required nutrients. In contrast, production of many essential amino acids using ammonia by an Elusimicrobia endosymbiont of a cellulolytic protist inhabitant of $R$. speratus was inferred from an analysis of its genome and they are accessible to the host via digestion of the protist or by uncharacterized transport mechanisms (Hongoh et al. 2008a).

Although Spirochaetes have been well documented in termite gut communities (Paster \& Dewhirst 2000; Rosenthal et al. 2011; Köhler et al. 2012), no single OTU was abundant in either termite host species examined. Hydrogen metabolism has been proposed as one of the functions of spirochaetes in termite guts (Rosenthal et al. 2011) but further characterization is necessary. Combined OTUs assigned to the Spirochaetes were present and $>1 \%$ of the sequence reads in all insects except two wild-caught 
$P$. americana samples, yet only three occurrences were noted where single OTUs were $>1 \%$ of the sequence reads for a sample (Additional file 3: Table S2). Since the OTUs were defined at $\geq 95 \%$ sequence identity, the Spirochaetes detected in the termites exhibited greater within-sample diversity and evenness of abundance than that observed for OTUs assigned to the Bacteroidia or Clostridia classes in the same termites.

\section{Protist-associated OTUs predominate the microbiota of insects lacking fully functional Blattabacterium endosymbionts}

Nearly all cockroaches harbor the obligate intracellular mutualist, Blattabacterium, and its absence in all termites except Mastotermes presents an opportunity to explore the possibility of mutualist replacement within the dictyopterans. We hypothesized that loss of Blattabacterium could only be tolerated if newly acquired microbes 1) were abundant in the gut (a proxy for being well-adapted to the host environment and an important member of the community), 2) could be reliably transmitted to offspring and 3) capable of supplying nutrients required by the host. Results from this survey of the microbiota indicate that microbiota samples from Heterotermes, which lacks Blattabacterium, had the least amount of OTU diversity and evenness and exhibited the least community profile variability, as indicated by the low average distance (Table 1). Conversely, microbiota samples from $P$. americana, which harbors Blattabacterium with all of its essential amino acid biosynthesis pathways intact, were more variable for relative abundance, OTU richness, evenness and thus exhibited the greatest distance between samples from the same host. Average distances for the microbiota samples from Cryptocercus and Mastotermes, whose Blattabacterium associates are deprived of many of the aforementioned biosynthetic pathways, were intermediate to those of Heterotermes and Periplaneta.

Accounting for a large proportion of the Heterotermes microbiota is a single Bacteroidia-assigned OTU (OTU_ 0035) that had a best hit ( $95 \%$ identity) to a nitrogenfixing (diazotrophic) endosymbiont of the cellulolytic trichonymphid protist, Pseudotrichonympha grassii, that resides in Coptotermes formosanus hindguts (Hongoh et al. 2008b) (Additional file 3: Table S2). The prevalence of OTU_0035 in the H. aureus samples suggests that it may be an essential member of the community, which would be reasonable if it too is diazotrophic and partnered with a cellulolytic protist. Soldiers and young instars obtain nutrients and gut microbes from the hindgut fluids of conspecifics via proctodeal trophallaxis (Machida et al. 2001; Nalepa et al. 2001). This practice would ensure the reliable communication of the gut microbiota that include oxygen-sensitive microbes, some of whom can fix nitrogen, a process that is inactivated by oxygen. The tight mutualism between the $\mathrm{N}_{2}$-fixing endosymbiont and the cellulolytic P. grasii combines functions essential for the termite to thrive on plant-based carbon sources in a single trophic mutualism. If the role of Blattabacterium is to provision amino acids and vitamins missing in the host's diet, its role would be tangential in the presence of the cellulolytic protist-diazotrophic bacteria symbiosis because the $\mathrm{N}_{2}$-fixing protist endosymbiont can generate the same assortment of nutrients and Blattabacterium cannot degrade cellulose or fix atmospheric nitrogen.

Both Mastotermes and Cryptocercus have cellulosebased diets, exhibit trophallaxic behavior and still retain Blattabacterium, albeit with reduced genomes and diminished nutrient provisioning abilities. Unlike Blattabacterium in other cockroaches, which are capable of making all ten essential amino acids, the endosymbiont in Mastotermes and Cryptocercus encode the genes for the production of only five or six essential amino acids, respectively (Neef et al. 2011; Sabree et al. 2012). In most cases members of the Bacteroidia were the most abundant in Cryptocercus and Mastotermes, but no single OTU was as abundant as OTU_0035 in Heterotermes.

Two abundant, protist-associated bacteroidial OTUs (OTU_1551 and OTU_0214) in Mastotermes were only 93\% identical to OTU_0035, which suggests little gene flow between these bacteroidial taxa and isolation of their protist hosts within their respective termite hosts would support this. The devescovinid Mixotricha paradoxa is abundant in Mastotermes but the functions of its associated bacteroidia remain to be determined. Additional OTUs detected in Mastotermes that were related to bacterial symbionts of gut protists were taxonomically assigned to the Elusimicrobia and Tenericutes. Protists are abundant symbiotic inhabitants of termites (Ohkuma \& Brune 2011; Desai \& Brune 2012), which likely contributes to the relative abundance of their associated bacteria. The low percent identity to available taxonassigned sequences suggests that this is the first published detection of the Tenericutes-assigned gut protist symbiont in $M$. darwiniensis. It is possible that the $M$. darwiniensis Elusimicrobia detected in this study plays a role in life of its host that is analogous to that of $R$. speratus protist symbionts given that their hosts have similar diets.

Many of the Bacteroidia and Clostridia-assigned OTUs in the $P$. americana gut communities had best hits to amplicons obtained from either Shelfordella lateralis (Schauer et al. 2012) or various termites. S. lateralis and $P$. americana are both part of the Blattidae (Blattoidea) family, which suggests that the shared OTUs may represent taxa that are well-adapted to their cockroach hosts and were acquired following divergence of the ShelfordellaPeriplaneta (Blattoidea) and Cryptocercus (Blaberoidea) 
clades. Deep sampling of gut microfloral diversity of other host taxa in both of these superfamilies is necessary to test this hypothesis. The role of taxa shared by Periplaneta and Shelfordella in cockroach host development and/or trophisms remain to be characterized. Finally, the relative abundance of pyrotags representing the abundant OTUs assigned to the Bacteroidia and Clostridia classes varied significantly (T-test: $\mathrm{p}<0.0003$ ) between the samples obtained from wild-caught and lab-reared $P$. americana. This supports the hypothesis that $P$. americana harbors some host-specific bacteria, as evidenced by the ordination analyses, but diet and/or habitat can impact their prevalence.

\section{Ammonia-oxidizing and sulfate-reducing bacteria in cockroaches}

OTUs assigned to the Planctomycetes and Deltaproteobacteria were largely shared by and unique to the cockroaches. Known physiological characteristics of Planctomycetes members are the lack of peptidoglycan in their cell walls, intracellular compartmentalization, sterol biosynthesis, and budding reproduction (for review (Fuerst \& Sagulenko 2011)). Additionally, so-called 'annamox' members are chemoautotrophic anaerobes capable of oxidizing ammonia to dinitrogen and are being successfully exploited for energy-efficient removal of nitrogenous wastes in wastewater treatment (Siegrist et al. 2008; Shi et al. 2013). Ammonia comprises much of the nitrogenous wastes externally excreted by cockroaches (Cochran 1985) and annamox Planctomycetes present in their hindguts may utilize this surplus to generate ATP via the annamoxosome (van Niftrik \& Jetten 2012) and, by effect, may have a detoxifying effect by reducing the concentration of ammonia present in the hindgut.

Deltaproteobacteria-assigned OTUs in Cryptocercus and Periplaneta hindguts had best hits to amplicons that were assigned to the Desulfobacteriaceae and Desulfovibrionaceae families. Many cultivated members of both groups are strict anaerobes residing in marine sediments that are capable of coupling sulfate-reduction and energy production (Muyzer \& Stams 2008). Additionally, Candidatus "Desulfovibrio trychonymphae", an endosymbiont of an anaerobic $R$. speratus-inhabiting protist, has also been shown to have and express genes involved in sulfate-reduction (Sato et al. 2009), but it is not clear if this is their primary function in the hindgut microbiome.

\section{Conclusions}

The gut microbiomes of dictyopteran insects surveyed in this study are comprised of many bacteria from the same class-level taxonomic groups (e.g. Bacteroidia, Clostridia, Spirochaetes and Bacilli) but distinct sub-lineages were observed when OTUs were resolved at the $\geq 95 \%$ sequence identity cutoff, indicating the presence of many relatively abundant host-specific taxa. The gut communities of the strict wood-feeding insects had bacterial taxa known to be associated with cellulolytic protists and fewer shared OTUs while the OTU diversity was generally greater and more variable in the omnivorous $P$. americana. If the abundant endosymbiont of the $H$. aureus cellulolytic trichonymphid protist is diazotrophic and capable of provisioning amino acids to its protist host that is itself digested by the termite, then acquisition of this and other gut bacterial-protist or bacterial symbioses that facilitated wood-feeding could have contributed to the shift in nutritional reliance from Blattabacterium to the gut microbiome. M. darwiniensis and Cryptocercus have microbiomes that are more diverse than that of $H$. aureus, harbor cellulolytic protists with bacterial symbionts and also sport many of the host physiological and behavioral modifications observed in $H$. aureus. Given that M. darwiniensis and Cryptocercus are sister taxa, both harbor Blattabacterium spp. that are functionally reduced and $M$. darwiniensis is basal to termites, it is possible that these host gut microbiomes represent intermediate stages of a more stable community that is essential for wood-feeding. Unlike in M. darwiniensis and Cryptocercus, the $P$. americana Blattabacterium is equipped to provision vitamins and a near-complete suite of amino acids to its host, which may reduce its reliance upon the gut microbiome for these functions. Elevated average distances between within-group samples for $P$. americana gut microbiota membership suggest this possibility but the presence of shared OTUs between the wild-caught and lab-reared $P$. americana indicates a host-specific microbiota that is present regardless of diet or lifestyle. The functions of these members remain to be determined.

Deep sequencing has helped to identify a number of previously undetected taxa in this study, and others seeking to profile cockroach and termite microbiomes (Köhler et al. 2012; Schauer et al. 2012; Huang et al. 2013; Boucias et al. 2013) that likely represent novel strains, species or genera, indicating that the guts of dictyopteran insect, of which there are about 8,500 species, contain a wealth of novel bacterial diversity. It is clear that further functional characterization of abundant cockroach and termite gut microbiome members is necessary and will likely reveal some new biological activities.

\section{Methods}

\section{DNA extraction and multiplexed sample preparation}

Entire guts were dissected from fresh or ethanol-preserved specimens from the following sources: Heterotermes aureus (Tucson, Arizona, USA; July 2008), Mastotermes darwiniensis (Marlow Lagoon, Northern Territory, Australia), Cryptocercus punctulatus (Mountain Lake, Virginia, USA), wild-caught Periplaneta americana (near the University of Arizona gymnasium, Tucson, Arizona, USA, July 2010, $33^{\circ} \mathrm{C}$ and $25 \%$ relative humidity), lab-reared $P$. americana (lab colony fed on dog food containing $28 \%$ amino acids, 
provided water ad libatum and maintained at $24 \mathrm{C}$ and $35 \%$ relative humidity). Three adult individuals captured from each habitat were sampled. DNA was prepared using the Power Soil DNA Isolation Kit (MoBio, San Diego, USA) according to the supplied protocol. $50 \mathrm{ng}$ of template DNA was used in PCR amplifications performed in triplicate in $30 \mu \mathrm{L}$ reactions containing $0.4 \mu \mathrm{M}$ bacteriaspecific forward primer (TAXX-926 F: 5' -\{adapter\}\{barcode\}-AAACTYAAAKGAATTGACGG-3'; (Lane 1991; Engelbrektson et al. 2010)) that were uniquely barcoded for multiplexing samples, $0.4 \mu \mathrm{M}$ nonbarcoded universal primer (TB-1392R: 5'-\{adapter\}-TACGGYTACCTTGT TACGACTT-3'; (Ferris et al. 1996; Engelbrektson et al. 2010)) (see Additional file 4: Materials for primer sequences), $0.55 \mathrm{U}$ Phusion Taq DNA polymerase (New England Biolabs, Massachusetts, USA), and $1 \mathrm{mM}$ dNTP mix (Promega, Wisconsin, USA). Selected primers were used to amplify the hypervariable V6-V9 regions of the 16S rRNA gene (Sogin et al. 2006; Roesch et al. 2007). Reactions were initially denatured at $98^{\circ} \mathrm{C}$ for $1 \mathrm{~min}$, followed by 25 cycles of $98^{\circ} \mathrm{C}$ for $10 \mathrm{sec}, 55^{\circ} \mathrm{C}$ for $10 \mathrm{sec}$ and $72^{\circ} \mathrm{C}$ for $15 \mathrm{sec}$ and a final, single cycle of $72^{\circ} \mathrm{C}$ for $10 \mathrm{~min}$. Amplification was confirmed by gel electrophoresis, and PCR products from amplifications performed in triplicate were pooled, purified using AmPure magnetic beads (Beckman Coulter, Indianapolis, USA) and quantified using the Qubit fluorometer (Life Technologies, New York, USA). Barcoded PCR products were combined, at a final concentration of $0.45 \mathrm{ng}$ per reaction, into a single, multiplexed sample that was submitted to the University of Arizona Genomics Center for pyrosequencing on a Roche 454 FLX-Titanium system.

\section{Pyrotag processing and analysis}

402,054 raw, barcoded amplicon sequences ("pyrotags") were obtained from the pyrosequencing run. These were processed within the CLC Genomics Workbench (www. clcbio.com) to trim low-quality regions ( $<27$ Phred score) from each pyrotag and to remove reads that were less than $400 \mathrm{bp}$ in length and/or had one or more errors in the forward primer or barcode regions. MOTHUR was used for further pyrotag processing (version 1.24, (Schloss et al. 2009)) (for details, see Additional file 4: Materials), and pyrotags having $\geq 95 \%$ identity were clustered into operational taxonomic units (OTUs) in MOTHUR (cluster.split, method = furthest). OTUs that did not have at least two pyrotags present in at least two samples were excluded from our dataset to minimize the impact of possible contaminants and extremely rare OTUs on our analyses. OTUs were taxonomically classified by blastn-based (BLAST+, version 2.2.26; parameters -task blastn -outfmt 6 -evalue 1e-50; (Camacho et al. 2009)) searches of Silva (version 108, (Pruesse et al. 2007)) and NCBI 'nt' nucleotide databases with representative sequences of each OTU. Acceptable alignments included only those for which $>85 \%$ of the query and 'hit' (or 'subject' in BLAST+ parlance) sequences were aligned. Available taxonomic information for the top hits were used to define OTUs. OTUs having hits to plastids or mitochondria were removed from the analysis. We used the abundance-based coverage estimator (ACE) (Chao et al. 1993) to conservatively predict the number of OTUs in each sample (richness) and the inverse Simpson diversity index (Simpson 1949) to estimate OTU evenness. Prior to our comparative community analyses, we generated a size-standardized subset of the original data that, in terms of the relative abundances of OTUs in each sample, was not significantly different (paired t-test, $\mathrm{p}>0.05$ ) from the original dataset by randomly sampling pyrotags from each OTU to 2,050 per sample for all samples. The subsampled dataset was used as input to test and visualize within-group and between-group differences using Multi-Response Permutation Procedures (MRPP) (Mielke 1984) and Nonmetric Multidimensional Scaling (NMS) (Kruskal 1964) within the PC-ORD (version 4.25) software package (McCune \& Mefford 1999). The Bray-Curtis distance measure was used in both comparative analyses and a combination of low stress and maximum stability was sought for the NMS solution.

\section{Sequencing data accession number}

Representative OTU names and corresponding NCBI GenBank accession numbers can be found in Additional file 4 .

\section{Additional files}

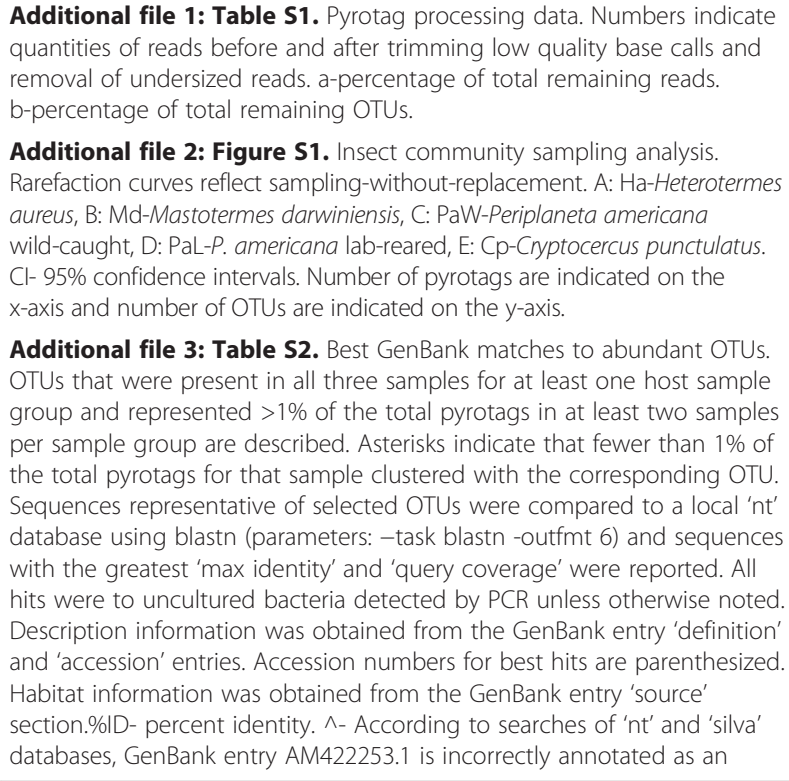

Additional file 1: Table S1. Pyrotag processing data. Numbers indicate quantities of reads before and after trimming low quality base calls and removal of undersized reads. a-percentage of total remaining reads. b-percentage of total remaining OTUs.

Additional file 2: Figure S1. Insect community sampling analysis. Rarefaction curves reflect sampling-without-replacement. A: Ha-Heterotermes aureus, B: Md-Mastotermes darwiniensis, C: PaW-Periplaneta americana wild-caught, D: PaL-P. americana lab-reared, E: Cp-Cryptocercus punctulatus. $\mathrm{Cl}-95 \%$ confidence intervals. Number of pyrotags are indicated on the $x$-axis and number of OTUs are indicated on the $y$-axis.

Additional file 3: Table S2. Best GenBank matches to abundant OTUs OTUs that were present in all three samples for at least one host sample group and represented $>1 \%$ of the total pyrotags in at least two samples per sample group are described. Asterisks indicate that fewer than $1 \%$ of the total pyrotags for that sample clustered with the corresponding OTU. Sequences representative of selected OTUs were compared to a local ' $n t$ ' database using blastn (parameters: -task blastn -outfmt 6) and sequences with the greatest 'max identity' and 'query coverage' were reported. All hits were to uncultured bacteria detected by PCR unless otherwise noted. Description information was obtained from the GenBank entry 'definition' and 'accession' entries. Accession numbers for best hits are parenthesized. Habitat information was obtained from the GenBank entry 'source' section.\%ID- percent identity. ^ - According to searches of ' $\mathrm{nt}$ ' and 'silva' databases, GenBank entry AM422253.1 is incorrectly annotated as an 
"Uncultured Eubacterium sp". and would not be a member of the Firmicutes. \&- Best blast hit was to a bacterial isolate.

Additional file 4. Representative OTUs. Text document includes representative OTU names and corresponding NCBI GenBank accession numbers.

\section{Competing interests}

The authors declare that they have no competing interests.

\section{Author's contributions}

ZLS and NAM designed the experiments, collaborated on analyses and wrote the manuscript. Both authors read and approved the final manuscript.

\section{Acknowledgements}

Funding was provided by the US National Science Foundation (awards 0626716 and 1062363 to NAM) and from Yale University. We thank Eli Powell and Yogeshwar Kelkar for technical assistance. We are grateful to Christine Nalepa and Xuguo Zhou for thoughtful conversations and Cryptocercus specimens, Nathan Lo for Mastotermes specimens, Gaelen Burke and Kevin Vogel for wild Periplaneta specimens and Emily Walsh for assistance in the preparation of this manuscript.

\section{Author details}

${ }^{1}$ Department of Ecology and Evolutionary Biology, Yale University, New Haven, CT 06511, USA. 'Department of Evolution, Ecology and Organismal Biology, The Ohio State University, Columbus, OH 43210, USA. ${ }^{3}$ Section of Integrative Biology, The University of Texas at Austin, Austin, TX 78712, USA.

\section{Received: 22 January 2014 Accepted: 28 February 2014}

\section{Published: 11 March 2014}

\section{References}

Abt B, Han C, Scheuner C, Lu M, Lapidus A, Nolan M, Lucas S, Hammon N, Deshpande S, Cheng JF, Tapia R, Goodwin LA, Pitluck S, Liolios K, Pagani I, Ivanova N, Mavromatis K, Mikhailova N, Huntemann M, Pati A, Chen A, Palaniappan K, Land M, Hauser L, Brambilla EM, Rohde M, Spring S, Gronow S, Göker M, Woyke T et al (2012) Complete genome sequence of the termite hindgut bacterium Spirochaeta coccoides type strain (SPN1(T)), reclassification in the genus Sphaerochaeta as Sphaerochaeta coccoides comb. nov. and emendations of the family Spirochaetaceae and the genus Sphaerochaeta. Stand Genomic Sci 6:194-209

Bell WJ, Roth LM, Nalepa CA (2007) Cockroaches: Ecology, Behavior, and Natural History. The Johns Hopkins University Press, Baltimore

Benemann JR (1973) Nitrogen fixation in termites. Science 181:164-165

Boucias DG, Cai Y, Sun Y, Lietze VU, Sen R, Raychoudhury R, Scharf ME (2013) The hindgut lumen prokaryotic microbiota of the termite Reticulitermes flavipes and its responses to dietary lignocellulose composition. Mol Ecol 22:1836-53

Camacho C, Coulouris G, Avagyan V, Ma N, Papadopoulos J, Bealer K, Madden TL (2009) BLAST+: architecture and applications. BMC Bioinforma 10:421

Carpenter KJ, Horak A, Chow L, Keeling PJ (2011) Symbiosis, morphology, and phylogeny of Hoplonymphidae (Parabasalia) of the wood-feeding roach Cryptocercus punctulatus. J Eukaryot Microbiol 58:426-436

Chao A, Ma M-C, Yang MCK (1993) Stopping rule and estimation for recapture debugging with unequal detection rates. Biometrika 80:193-201

Cochran DG (1985) Nitrogen excretion in cockroaches. Annu Rev Entomol 30:29-49

Desai MS, Brune A (2012) Bacteroidales ectosymbionts of gut flagellates shape the nitrogen-fixing community in dry-wood termites. ISME J 6:1302-1313

Engel P, Moran NA (2013) The gut microbiota of insects - diversity in structure and function. FEMS Microbiol Rev 37:699-735

Engelbrektson A, Kunin V, Wrighton KC, Zvenigorodsky N, Chen F, Ochman H, Hugenholtz P (2010) Experimental factors affecting PCR-based estimates of microbial species richness and evenness. ISME J 4:642-647

Ferris MJ, Muyzer G, Ward DM (1996) Denaturing gradient gel electrophoresis profiles of $16 \mathrm{~S}$ rRNA-defined populations inhabiting a hot spring microbial mat community. Appl Environ Microbiol 62:340-346

Fuerst JA, Sagulenko E (2011) Beyond the bacterium: planctomycetes challenge our concepts of microbial structure and function. Nat Rev Microbiol 9:403-413
Garnier M, Foissac X, Gaurivaud P, Laigret F, Renaudin J, Saillard C, Bové JM (2001) Mycoplasmas, plants, insects vectors: a matrimonial triangle. Life Sci 32:923-928

Gasparich GE (2010) Spiroplasmas and phytoplasmas: microbes associated with plant hosts. Biologicals 38:193-203

Geissinger O, Herlemann DP, Mörschel E, Maier UG, Brune A (2009) The ultramicrobacterium "Elusimicrobium minutum" gen. nov., sp. nov., the first cultivated representative of the termite group 1 phylum. Appl Environ Microbiol 75:2831-2840

Haselkorn TS, Cockburn SN, Hamilton PT, Perlman SJ, Jaenike J (2013) Infectious adaptation: potential host range of a defensive endosymbiont in Drosophila. Evolution 67:934-945

Herlemann DP, Geissinger O, Brune A (2007) The termite group I phylum is highly diverse and widespread in the environment. Appl Environ Microbiol 73:6682-6685

Hongoh Y (2010) Diversity and genomes of uncultured microbial symbionts in the termite gut. Biosci Biotechnol Biochem 74:1145-1151

Hongoh Y, Ohkuma M, Kudo T (2003) Molecular analysis of bacterial microbiota in the gut of the termite Reticulitermes speratus (Isoptera; Rhinotermitidae). FEMS Microbiol Ecol 44:231-242

Hongoh Y, Sharma VK, Prakash T, Noda S, Taylor TD, Kudo T, Sakaki Y, Toyoda A, Hattori M, Ohkuma M (2008a) Complete genome of the uncultured Termite Group 1 bacteria in a single host protist cell. Proc Natl Acad Sci USA 105:5555-5560

Hongoh Y, Sharma VK, Prakash T, Noda S, Toh H, Taylor TD, Kudo T, Sakaki Y, Toyoda A, Hattori M, Ohkuma M (2008b) Genome of an endosymbiont coupling N2 fixation to cellulolysis within protist cells in termite gut. Science 322:1108-1109

Huang XF, Bakker MG, Judd TM, Reardon KF, Vivanco JM (2013) Variations in diversity and richness of gut bacterial communities of termites (Reticulitermes flavipes) fed with grassy and woody plant substrates. Microb Ecol 65:531-536

Isanapong J, Goodwin L, Bruce D, Chen A, Detter C, Han J, Han CS, Held B, Huntemann M, Ivanova N, Land ML, Mavromatis K, Nolan M, Pati A, Pennacchio L, Pitluck S, Szeto E, Tapia R, Woyke T, Rodrigues JL (2012) High-quality draft genome sequence of the Opitutaceae bacterium strain TAV1, a symbiont of the wood-feeding termite Reticulitermes flavipes. J Bacteriol 194:2744-2745

Köhler T, Dietrich C, Scheffrahn RH, Brune A (2012) High-resolution analysis of gut environment and bacterial microbiota reveals functional compartmentation of the gut in wood-feeding higher termites (Nasutitermes spp.). Appl Environ Microbiol 78:4691-4701

Kruskal JB (1964) Nonmetric multidimensional scaling: A numerical method. Psychometrika 29:115-129

Kudo T, Ohkuma M, Moriya S, Noda S, Ohtoko K (1998) Molecular phylogenetic identification of the intestinal anaerobic microbial community in the hindgut of the termite, Reticulitermes speratus, without cultivation. Extremophiles 2:155-161

Lane DJ (1991) 16S/23S rRNA sequencing. In: Stackebrandt E, Goodfellow M (eds) Nucleic acid techniques in bacterial systematics. John Wiley and Sons, New York, pp 115-175

Lo N, Bandi C, Watanabe H, Nalepa C, Beninati T (2003) Evidence for cocladogenesis between diverse dictyopteran lineages and their intracellular endosymbionts. Mol Biol Evol 20:907-913

Machida M, Kitade O, Miura T, Matsumoto T (2001) Nitrogen recycling through proctodeal trophallaxis in the Japanese damp-wood termite Hodotermopsis japonica (Isoptera, Termopsidae). Insect Soc 48:52-56

Mattéotti C, Thonart P, Francis F, Haubruge E, Destain J, Brasseur C, Bauwens J, De Pauw E, Portetelle D, Vandenbol M (2011) New glucosidase activities identified by functional screening of a genomic DNA library from the gut microbiota of the termite Reticulitermes santonensis. Microbiol Res 166:629-642

McCune B, Mefford MJ (1999) PC-ORD: Multivariate Analysis of Ecological Data, ver. 4. MjM Software Design, Gleneden Beach, OR

Merrill W, Cowling EB (1966) Role of nitrogen in wood deterioration: Amounts and distribution of nitrogen in tree stems. Can J Bot 44:1555-1580

Mielke PW (1984) Meteorological applications of permutation techniques based on distance functions. In: Krishnaiah PR, Sen PK (eds) Handbook of Statistics, vol 4. Elsevier Science, New York, pp 813-830

Moran NA, McCutcheon JP, Nakabachi A (2008) Genomics and evolution of heritable bacterial symbionts. Annu Rev Genet 42:165-90

Muyzer G, Stams AJ (2008) The ecology and biotechnology of sulphate-reducing bacteria. Nat Rev Microbiol 6:441-54 
Nalepa C (2011) Altricial development in wood-feeding cockroaches: The key antecedent of termite eusociality. In: Bignell DE, Roisin Y, Lo N (eds) Biology of termites: a modern synthesis. Springer, Dordrecht, pp 413-438, 438

Nalepa CA, Bignell DE, Bandi C (2001) Detritivory, coprophagy, and the evolution of digestive mutualisms in Dictyoptera. Insect Soc 48:194-201

Neef A, Latorre A, Peretó J, Silva FJ, Pignatelli M, Moya A (2011) Genome economization in the endosymbiont of the wood roach Cryptocercus punctulatus due to drastic loss of amino acid synthesis capabilities. Genome Biol Evol 3:1437-1448

Ohkuma M, Brune A (2011) Diversity, structure, and evolution of the termite gut microbial community. In: Bignell DE, Roisin Y, Lo N (eds) Biology of Termites: a Modern Synthesis. Springer, Dordrecht, pp 413-438, 438

Ohkuma M, Kudo T (1996) Phylogenetic diversity of the intestinal bacterial community in the termite Reticulitermes speratus. Appl Environ Microbiol 62:461-468

Ohkuma M, Noda S, Kudo T (1999) Phylogenetic diversity of nitrogen fixation genes in the symbiotic microbial community in the gut of diverse termites. Appl Environ Microbiol 65:4926-4934

Paster BJ, Dewhirst FE (2000) Phylogenetic foundation of spirochetes. J Mol Microbiol Biotechnol 2:341-344

Potrikus CJ, Breznak JA (1977) Nitrogen-fixing Enterobacter agglomerans isolated from guts of wood-eating termites. Appl Environ Microbiol 33:392-399

Pruesse E, Quast C, Knittel K, Fuchs BM, Ludwig W, Peplies J, Glöckner FO (2007) SILVA: a comprehensive online resource for quality checked and aligned ribosomal RNA sequence data compatible with ARB. Nucleic Acids Res 35:7188-7196

Roesch LF, Fulthorpe RR, Riva A, Casella G, Hadwin AK, Kent AD, Daroub SH, Camargo FA, Farmerie WG, Triplett EW (2007) Pyrosequencing enumerates and contrasts soil microbial diversity. ISME J 1:283-90

Rosenthal AZ, Matson EG, Eldar A, Leadbetter JR (2011) RNA-seq reveals cooperative metabolic interactions between two termite-gut spirochete species in co-culture. ISME J 5:1133-1142

Sabree ZL, Kambhampati S, Moran NA (2009) Nitrogen recycling and nutritional provisioning by Blattabacterium, the cockroach endosymbiont. Proc Natl Acad Sci USA 106:19521-19526

Sabree ZL, Huang CY, Arakawa G, Tokuda G, Lo N, Watanabe H, Moran NA (2012) Genome shrinkage and loss of nutrient-providing potential in the obligate symbiont of the primitive termite Mastotermes darwiniensis. Appl Environ Microbiol 78:204-210

Sabree ZL, Huang CY, Okusu A, Moran NA, Normark BB (2013) The nutrient supplying capabilities of Uzinura, an endosymbiont of armoured scale insects. Environ Microbiol 15:1988-1999

Sato T, Hongoh Y, Noda S, Hattori S, Ui S, Ohkuma M (2009) Candidatus "Desulfovibrio trichonymphae", a novel intracellular symbiont of the flagellate Trichonympha agilis in termite gut. Environ Microbiol 11(4):1007-15

Scharf ME, Karl ZJ, Sethi A, Boucias DG (2011) Multiple levels of synergistic collaboration in termite lignocellulose digestion. PLoS One 6:e21709

Schauer C, Thompson CL, Brune A (2012) The bacterial community in the gut of the cockroach Shelfordella lateralis reflects the close evolutionary relatedness of cockroaches and termites. Appl Environ Microbiol 78:2758-2767

Schleifer K-H (2009) Phylum XIII. Firmicutes Gibbons and Murray 1978, 5 (Firmacutes [sic] Gibbons and Murray 1978, 5). In: De Vos P, Garrity GM, Jones D, Krieg NR, Ludwig W, Rainey FA, Schleifer K-H, Whitman WB (eds) Bergey's Manual of Systematic Bacteriology Vol. 3: The Firmicutes, 2nd edn. Springer, Heidelberg/New York. ISBN 978-0387950419

Schloss PD, Handelsman J (2003) Biotechnological prospects from metagenomics. Curr Opin Biotechnol 14:303-310

Schloss PD, Westcott SL, Ryabin T, Hall JR, Hartmann M, Hollister EB, Lesniewski RA, Oakley BB, Parks DH, Robinson CJ, Sahl JW, Stres B, Thallinger GG, Van Horn DJ, Weber CF (2009) Introducing mothur: open-source, platformindependent, community-supported software for describing and comparing microbial communities. Appl Environ Microbiol 75:7537-7541

Shi Y, Hu S, Lou J, Lu P, Keller J, Yuan Z (2013) Nitrogen removal from wastewater by coupling anammox and methane-dependent denitrification in a membrane biofilm reactor. Environ Sci Technol 47:11577-11583

Siegrist H, Salzgeber D, Eugster J, Joss A (2008) Anammox brings WWTP closer to energy autarky due to increased biogas production and reduced aeration energy for N-removal. Water Sci Technol 57:383-8

Simpson EH (1949) Measurement of diversity. Nature 163:688-688

Sogin ML, Morrison HG, Huber JA, Mark Welch D, Huse SM, Neal PR, Arrieta JM, Herndl GJ (2006) Microbial diversity in the deep sea and the underexplored "rare biosphere". Proc Natl Acad Sci USA 103:12115-12120
Strassert JF, Köhler T, Wienemann TH, Ikeda-Ohtsubo W, Faivre N, Franckenberg S, Plarre R, Radek R, Brune A (2012) Candidatus "Ancillula trichonymphae', a novel lineage of endosymbiotic Actinobacteria in termite gut flagellates of the genus Trichonympha. Environ Microbiol 14:3259-3270

Tamschick S, Radek R (2013) Colonization of termite hindgut walls by oxymonad flagellates and prokaryotes in Incisitermes tabogae, I. marginipennis and Reticulitermes flavipes. Eur J Protistol 49:1-14

Tartar A, Wheeler MM, Zhou X, Coy MR, Boucias DG, Scharf ME (2009) Parallel metatranscriptome analyses of host and symbiont gene expression in the gut of the termite Reticulitermes flavipes. Biotechnol Biofuels 2:25

Tayasu I, Sugimoto A, Wada E, Abe T (1994) Xylophagous termites depending on atmospheric nitrogen. Naturwissenschaften 81:229-231

Tracy BP, Jones SW, Fast AG, Indurthi DC, Papoutsakis ET (2012) Clostridia: the importance of their exceptional substrate and metabolite diversity for biofuel and biorefinery applications. Curr Opin Biotechnol 23:364-81

Tringe SG, Hugenholtz P (2008) A renaissance for the pioneering 16S rRNA gene. Curr Opin Microbiol 11:442-446

van Niftrik L, Jetten MS (2012) Anaerobic ammonium-oxidizing bacteria: unique microorganisms with exceptional properties. Microbiol Mol Biol Rev 76:585-96

Wertz JT, Kim E, Breznak JA, Schmidt TM, Rodrigues JL (2012) Genomic and physiological characterization of the Verrucomicrobia isolate Diplosphaera colitermitum gen. nov., sp. nov., reveals microaerophily and nitrogen fixation genes. Appl Environ Microbiol 78:1544-1555

Yamada A, Inoue T, Noda S, Hongoh Y, Ohkuma M (2007) Evolutionary trend of phylogenetic diversity of nitrogen fixation genes in the gut community of wood-feeding termites. Mol Ecol 16:3768-3777

doi:10.1186/2193-1801-3-138

Cite this article as: Sabree and Moran: Host-specific assemblages typify gut microbial communities of related insect species. SpringerPlus 2014 3:138

\section{Submit your manuscript to a SpringerOpen ${ }^{\circ}$ journal and benefit from:}

- Convenient online submission

- Rigorous peer review

- Immediate publication on acceptance

- Open access: articles freely available online

- High visibility within the field

- Retaining the copyright to your article

Submit your next manuscript at $>$ springeropen.com 